\title{
工业污水中化学需氧量测定的影响因素分析
}

\author{
周娣 \\ 盐城市大丰区环境监测站 \\ DOI:10.32629/eep.v2i9.420
}

[摘 要] 参考《HJ828-2017》方法, 借助重络酸盐方法对工业废水的化学需氧量进行测量,并评估测量的准确程度。在检测分析期间, 重点 阐述多种因素对于测量结果不确定性的影响,并实施定量分析,确定对测量结果产生影响的因素,使得分析的准确性不断提高。

[关键词] 工业污水; 化学需氧量; 测定; 影响因素; 分析

化学需氧量, 具体指的就是在强酸性的条件下, 重铬酸钾氧化水当中 有机物的需氧量, 能够对污水当中所含有机物量加以表示。通过对化学需 氧量的运用, 能够针对水中直链化合物有机污染物以及无机还原性物质进 行测定, 进而对水肿还原性物质被污染度真实地反映出来。目前阶段, 对工 业废水化学需氧量进行测定的标准就是《HJ $828-2017$ 》, 属于环 境保护标准法。然而, 在实际使用的过程中, 存在诸多影响因素, 使准确度 下降。为此, 要分析并评估不确定度, 了解影响检测结果的常见因素, 以实 现检测结果准确性的全面提升。

\section{1 测定方法分析}

均匀摇晃水样并移取出 10 毫升, 将其放置于容积为 250 毫升的雉形瓶 当中, 将适量的硫酸录溶液加入其中, 在均匀摇晃以后, 将 5 毫升的重铬酸 钾标准溶液添加其中, 同样进行均匀摇晃 ${ }^{[1]}$ 。随后, 连接雉形瓶与消解器回 流装置, 并在冷凝管的上方, 将 15 毫升的硫酸银-硫酸试剂缓慢地添加其中, 经过 2 小时回流以后冷却, 并将 45 毫升的蒸馏水加入其中, 对冷凝管进行冲 洗, 并由消解器内取出, 将试亚铁灵指示剂加入三滴, 随后选择硫酸亚铁铵 的标准滴定溶液进行滴定处理, 当溶液颜色从黄色向蓝绿色转变, 最终变 成红褐色以后即可结束。在整个过程中, 要对硫酸亚铁铵标准滴定溶液实 际消耗量进行详细地记录, 并开展空白试验。

\section{2 工业污水中化学需氧量测定的影响因素}

选择使用重铬酸盐的方法对水中的化学需氧量进行测定, 对测量结果 准确程度的影响因素主要包括以下几个方面: 通过研究与分析, 希望在后 期测定中严格控制存在的影响因素。

2.1 反应时间与温度测定

在消解的过程中, 溶液应缓慢沸腾, 尽量不要出现懪沸的情况。若发生 爆沸的现象, 即代表溶液内有局部过热的问题, 使溶液更容易逸出来并损 失 ${ }^{[2]}$ 。而没有发生反应的重铬酸钾, 会导致分析的结果不断提高, 影响测定 结果的准确性。如果加热的温度偏低, 无法完全氧化, 就会导致测定的结果 过低的情况发生。在多次实验以后, 消解器加热的温度恒定在 270 摄氏度, 数值最为稳定。

选择不同的加热时间, 测定标准物质化学需氧量: (1) 加热20分钟 后, COD值 $32.8 \mathrm{mg} / \mathrm{L}$ 时, 数值为 $25, \mathrm{COD}$ 值 $104 \mathrm{mg} / \mathrm{L}$ 时, 数值为 $90 ;$ （2) 加热 40 分钟后, COD值 $32.8 \mathrm{mg} / \mathrm{L}$ 时, 数值为 $28, \mathrm{COD}$ 值 $104 \mathrm{mg} / \mathrm{L}$ 时, 数值为 95 ; (3) 加热 70 分钟后, COD值 $32.8 \mathrm{mg} / \mathrm{L}$ 时, 数值为 $31, \mathrm{COD}$ 值 $104 \mathrm{mg} / \mathrm{L}$ 时, 数值为 $100 ;(4)$ 加热 100 分钟后, $\mathrm{COD}$ 值 $32.8 \mathrm{mg} / \mathrm{L}$ 时, 数值为 $32, \mathrm{COD}$ 值 $104 \mathrm{mg} / \mathrm{L}$ 时, 数值为 103; (5) 加热 120 分钟后, COD值 $32.8 \mathrm{mg} / \mathrm{L}$ 时, 数值为 33 , COD值 $104 \mathrm{mg} / \mathrm{L}$ 时, 数值为 103 。由此可见, 在加热时间控制为 $70-120$ 分钟之间, 具有最佳氧化 率, $\mathrm{COD}$ 数值与标准数值相接近且变化不明显 ${ }^{[3]}$ 。

2. 2 回流装置受污染
若回流装置被污染, 也会对化学需氧量测定结果的准确性产生影响, 导致测定的结果极高。所以, 在实际测定的过程中, 要求系统清洗回流管。 如果回流装置清洗干净后几天未使用, 那么在测定工作开展之前, 也一定 要使用蒸馏水进行反复冲洗, 有效规避空气内还原性气体对回流管造成污 染, 进而使得测定准确程度受到影响 ${ }^{[4]}$ 。

2. 3硫酸亚铁铵标准溶液浓度改变

在对化学需氧量进行测定之前, 也能够对硫酸亚铁铵溶液浓度事先标 定, 并结合酸式滴定管补正数值以及标定溶液温度的补正计算数值, 修改 实际消耗体积, 确定硫酸亚铁铵溶液的消耗量, 确定标准溶液具体浓度。在 实践过程中, 如果不针对滴定管与水溶液实施修正计算, 那么最终获取的 硫酸亚铁铵标准溶液浓度数值就会不准确, 对测定数值准确度产生不利影 响。开展滴定操作期间, 如果硫酸亚铁铵的标准溶液浓度过高, 就会出现滴 定误差较大的情况 ${ }^{[5]}$ 。而浓度过小, 那么溶液实际使用剂量就会增加, 最终 使得数值过小。现配置硫酸亚铁铵的标准溶液浓度应当是 $0.0500 \mathrm{~mol} / \mathrm{L}$, 而根据时间的改变, 此标准溶液的浓度变化规律如下:

(1) 1 天: 硫酸亚铁铵的消耗体积是 $25.00 \mathrm{~m} 1 、 25.01 \mathrm{ml}$, 而硫酸亚铁铵浓 度即为 $0.05005 \mathrm{mo} / / \mathrm{L}$; (2) 5 天: 硫酸亚铁铵的消耗体积是 $25.06 \mathrm{~m} 1 、 25.05 \mathrm{~m} 1$, 而硫酸亚铁铵浓度即为 $0.04952 \mathrm{~mol} / \mathrm{L}$; (3) 10 天: 硫酸亚铁铵的消耗体积是 $25.14 \mathrm{ml} 、 25.15 \mathrm{~m} 1$, 而硫酸亚铁铵浓度即为 $0.04930 \mathrm{~mol} / \mathrm{L}$; (4) 15 天: 硫酸亚 铁铵的消耗体积是 $25.20 \mathrm{ml} 、 25.23 \mathrm{ml}$, 而硫酸亚铁铵浓度即为 $0.04912 \mathrm{mo} / \mathrm{L}$; (5) 20 天: 硫酸亚铁铵的消耗体积是 $25.25 \mathrm{~m} 1 、 25.25 \mathrm{ml}$, 而硫酸亚铁铵浓度即 为 $0.04906 \mathrm{~mol} / \mathrm{L}$; (6) 25 天: 硫酸亚铁铵的消耗体积是 $25.32 \mathrm{~m} 1 、 25.31 \mathrm{~m} 1$, 而 硫酸亚铁铵浓度即为 $0.04894 \mathrm{~mol} / \mathrm{L}$; (7) 30 天: 硫酸亚铁铵的消耗体积是 $25.40 \mathrm{~m} 1 、 25.40 \mathrm{~m} 1$, 而硫酸亚铁铵浓度即为 $0.04882 \mathrm{~mol} / \mathrm{L}$ 。

由此可见, 根据浓度的标定发现, 经过配置的硫酸亚铁铵标准溶液的 浓度会伴随时间的延长而减小。究其原因, 低价铁氧化为三价铁。所以, 在每天领用事前, 要使用重铬酸钾的标准溶液对硫酸亚铁铵溶液浓度进行 标定, 且要求采用平行双样的方式 ${ }^{[6]}$ 。

2. 4 硫酸录加入剂量

氯离子是干扰化学需氧量的主要因素, 所以要通过提那家硫酸录溶液 进行消除处理。在回流以后, 氯离子即可结合硫酸录, 进而形成可溶性氯录 配合物。而加入硫酸录溶液剂量可以参考水样内的氯离子含量, 根据质量 比添加, 但最大的添加量不允许超过 2 毫升。如果溶液内所含氯离子超过每 升1000毫克, 即可稀释水样, 使得氯离子含量下降, 随后加以测定。需要注 意的是, 并非将硫酸录溶液加入量增加。这样一来, 就可以使测定的误差减 小, 以免硫酸录严重污染生态环境。

2.5 重铬酸钾标准物质

选择使用的重铬酸钾应当选择基准试剂, 并在100-110摄氏度的烘箱 


\section{加强园林绿化工程建设提升城市园林绿化水平}

陈兴霞

扬州市江都区园林工程有限公司

DOI:10.32629/eep.v2i9.449

[ 摘 要] 园林绿化工程是一项综合性较强的工程,其涉及的专业学科较多, 若想提升园林绿化工程建设水平,发挥园林绿化的作用,则提升园林 绿化管理工作是尤为重要的。本文就对园林绿化工程的建设原则及相应措施进行分析阐述, 以期为工程建设提供参考意见。

[关键词] 园林绿化工程; 建设原则; 措施

城市园林绿化作为增强城市生命力的基础设施, 是城市生态环境中较 为重要的组成部分, 不过现阶段城市园林绿化工程建设还存在一些问题, 这使得城市园林绿化效果得不到发挥。为此, 就应加强城市园林绿化建设 管理, 加快城市园林绿化事业的前进速度, 进而实现优美宜居城市的构建 目标, 推动人与自然的和谐发展。

\section{1 城市园林绿化工程的建设原则}

在城市园林绿化工程建设中应遵循几下基本原则, 以期提高园林绿化 工程的建设质量, 推动城市的进一步发展。

\section{1 功能性原则}

城市园林绿化工程建设是为完善城市生态环境, 为达到城市规划目标 而建的, 其具有观赏性、协调性、调节性等功能。所以在园林绿化工程设 计中, 应注重凸显园林绿化自身的功能, 并通过合理的规划布局及植物栽 培来凸显园林的观赏性及实用效果, 为人们营造舒适、健康的景观空间, 加强城市、自然及人三者间的联系。

1. 2 艺术性原则

园林绿化工程作为构建生态环境的重点项目, 不但要完善其自身功能 性, 美观性和艺术性也是不可忽略的重要内容。美观性自然指的是园林自 然景致的合理规划, 艺术性则是通过层次感及不同结构造型的设计来凸显 园林的独特性, 以此彰显区域特色, 使其成为城市规划发展中重要的标志。

1.3 经济性

内进行干燥, 以实现恒重目标。随后, 对重铬酸钾标准物质进行称取, 剂量 为 12.258 克, 将其加入到蒸馏水当中, 保证定容后为 1000 毫升, 成功获取重 铬酸钾标准溶液。应保证称重和配置准确, 以免标准溶液的准确性受到影 响而引起即为明显的测定误差 ${ }^{[7]}$ 。

一方面, 重铬酸钾标准溶液选用移液管不合理。在实际测定期间, 要求 移液管洁净且干燥。由于玻璃对于 $\mathrm{Cr}^{6+}$ 的吸附性较强, 使得玻璃壁的表面 出现薄膜与挂壁的情况, 移取的体积缺乏准确性, 使得结果的测定不准确。 对比分析洁净移液管与不洁净移液管测定结果, 发现前者结果均处于标准 浓度规定要求内, 而后者则明显高于标准浓度, 使得准确度受到直接影响。

另一方面, 重铬酸钾标准溶液的吸取量不合理。选择移液管对重铬酸 钾标准溶液进行移取的过程中, 如果吸取的移液量不准确, 初读与终读标 准存在差异, 无论是偏高亦或是偏低, 均会引起误差, 对测定结果准确程度 带来不利的影响。

\section{3 结束语}

综上所述, 根据以上研究与分析发现, 在实际测定期间, 硫酸亚铁铵溶 液实际浓度、重铬酸钾溶液配制以及移取准确程度、测定期间回流的温度 与时间以及样品内所含氯离子干扰等因素的存在, 均会对工业污水中化学 需氧量的测定结果准确性产生程度不同的影响。在这种情况下, 要求岗位
园林绿化工程的建设还需遵循经济性原则, 一方面要注重各项绿色指 标的合理性, 另一方面要充分考虑占地及制备配置问题, 以较少的资金成 本消耗创造更大的经济价值。

\section{4 可持续性}

园林景观不是某一时段的景观, 其是与城市化发展协调统一的建设项 目, 所以在园林绿化工程建设中, 要坚持可持续发展原则, 并根据现有的资 源条件, 对园林景观实行合理规划与设计, 既要保证一年四季景色的变化 效果, 还要注重与周边环境的协调适应, 满足城市长远规划的目标, 如此才 能推动城市建设与自然环境的协同发展, 营造和谐的生存空间。

\section{2 园林绿化工程建设措施}

2.1加强设计质量管理

在初期设计阶段, 建设方虽可向设计人员提出自己的想法和意见, 但 不建议其完全参与到设计中来, 左右设计思路, 以免影响整体设计效果。在 施工作业开展前, 设计和施工人员人员要对图纸及方案内容进行细致审查, 确保其与园林绿化工程建设要求相符, 尤其要加强对土地整改、土建及配 套设施施工、植被栽植及养护方面设计内容的检查, 对其中存在的问题予 以及时提出和改善, 做好细节处理, 增强图纸及方案的可行性。同时, 施工 作业前做好技术交底也是尤为必要的, 施工人员需对图纸及方案内容实行 详细了解, 对所需工艺技术予以明确掌握, 然后结合自身工作要求, 提出可 能出现的问题或影响因素, 做好预防和管控措施, 避免质量问题的出现。

工作人员不断提高自身的技术能力与责任心, 并参考具体的规定与标准要 求采取测定措施, 使用标准溶液实施质量控制工作, 只有这样, 才能够确保 样品检测准确程度不断提高。

\section{[参考文献]}

[1]解成岩.水质化学需氧量的测定经验的探讨与分析 [J].黑龙江环境 通报, 2019,43(2):28-29+36.

[2]杨华, 李东方, 申顺格. 工业污水中化学需氧量测定方法探讨 [J]. 建 筑工程技术与设计,2018,(26):3718.

[3]车承丹.臭氧工艺在市政污水和工业废水深度处理中的研究与应 用 [J].净水技术,2018,37(4):53-59+76.

[4]高兰玲.试论工业污水的处理方法及其化学需氧量分析[J].化工管 理,2014,(27):55.

[5]侯凯,杨咪,钱会, 等.黄河宁夏段氨氮、总磷及化学需氧量环境背景 值研究 [J].灌溉排水学报,2017,36(8):65-71.

[6]蔡舒婕.5一磺基水杨酸表面修饰纳米Ti02可见光光催化测定化学 需氧量[J].化工管理,2016,(35):73.

[7]高兰玲.试论工业污水的处理方法及其化学需氧量分析[J].化工管 理,2014,(27):213. 